Phase tracking algorithms detect both real and imaginary components of outer hair cell nonlinear membrane capacitance that exhibits dielectric loss.

\title{
Joseph Santos-Sacchi
}

Surgery (Otolaryngology), Neuroscience, and Cellular and Molecular Physiology, Yale University School of Medicine, 333 Cedar Street, New Haven, CT 06510, USA

Running title: Phase tracking capacitance estimates report on dielectric loss

Keywords: capacitance, displacement currents, cochlea amplification, prestin, macro-patch, voltageclamp, phase tracking

\section{Acknowledgments:}

This research was supported by NIH-NIDCD R01 DC016318 and R01 DC008130. We thank Fred Sigworth for comments on the manuscript.

\section{Send correspondence to:}

Joseph Santos-Sacchi

Surgery (Otolaryngology), Neuroscience, and Cellular and Molecular Physiology Yale University School of Medicine

BML 224, 333 Cedar Street

New Haven, CT 06510

Phone: (203) 785-7566

e-mail: joseph.santos-sacchi@yale.edu 
bioRxiv preprint doi: https://doi.org/10.1101/2022.01.01.474702; this version posted January 11, 2022. The copyright holder for this preprint (which was not certified by peer review) is the author/funder. All rights reserved. No reuse allowed without permission.

Santos-Sacchi

1/12/2022 12:10 AM

\begin{abstract}
Outer hair cell $(\mathrm{OHC})$ nonlinear membrane capacitance (NLC) represents voltage-dependent sensor charge movements within prestin (SLC26a5) that drive OHC electromotility. Dielectric loss, a shift in charge movement phase from purely "capacitive" to "resistive", is likely indicative of prestin's interaction with the viscous lipid bilayer and has been suggested to correspond to prestin power output. The frequency response of NLC in OHC membrane patches has been measured with phase tracking and complex capacitance methodologies. While the latter approach can directly determine the presence of dielectric loss by assessing charge movement both in and out of phase with driving voltage, the former has been suggested to fail in this regard. Here we show that standard phase tracking in the presence of dielectric loss does indeed register this loss. Such estimates of NLC correspond to the absolute magnitude of complex NLC, indicating that total charge movement regardless of phase is assessed, thereby validating past and present measures of NLC frequency response that limits its effectiveness at high frequencies. This observation has important implications for understanding prestin's role in cochlear amplification.
\end{abstract}




\section{Introduction}

Outer hair cell $(\mathrm{OHC})$ membrane capacitance $\left(\mathrm{C}_{m}\right)$ is composed of linear and voltage-dependent, nonlinear (NLC) parts (Ashmore, 1990; Santos-Sacchi, 1990, 1991). Both phase tracking methodology (Gale and Ashmore, 1997) and complex admittance assessment (Santos-Sacchi and Tan, 2020; SantosSacchi et al., 2021) have been used to estimate OHC NLC frequency response in membrane patches under voltage clamp. OHC NLC is a complex quantity $(\mathrm{CNLC})$, separable into real and imaginary components that represent SLC26a5 (prestin) voltage-sensor charge movements differing in phase by 90 degrees with respect to driving membrane voltage (Santos-Sacchi and Tan, 2020; Santos-Sacchi et al., 2021). This separation results from dielectric loss, a frequency-dependent accumulation of charge that moves through a "resistive" path, typically generating heat. The imaginary component of NLC can inform on this behavior across frequency. Dielectric loss may have its basis in the interaction of prestin with the viscous plasma membrane where it resides. Recent cryo-EM studies, including our own, on prestin have found evidence of significant interactions of membrane lipid around and within protein helices (Bavi et al., 2021; Butan et al., 2021; Ge et al., 2021) that confirms expectations from earlier physiological studies that identified effects of membrane lipid modification (Santos-Sacchi and Wu, 2004; Sfondouris et al., 2008; Fang et al., 2010; Zhai et al., 2020).

Recently, Rabbitt (Rabbitt, 2020) claimed that all past measures of OHC NLC, and indeed all phase tracking $C_{m}$ estimates in general, report only on the real component of complex capacitance. This is an important issue to clarify since it suggests that past measures of NLC have misjudged the OHC's influence on cochlear amplification by neglecting an important component (dielectric loss) of prestin charge movement that may correspond to power output of electromotility. Indeed, it was questioned whether identified low-pass prestin kinetics is a limiting factor for OHC performance in vivo (Gale and Ashmore, 1997; Santos-Sacchi and Tan, 2018; Santos-Sacchi, 2019; Santos-Sacchi et al., 2019; Santos-Sacchi and Tan, 2019, 2020).

Here, we report that, in the presence of dielectric loss, measures of NLC employing phase tracking methods, provide the absolute $\left(\sqrt{\operatorname{Re}(c N L C)^{2}+\operatorname{Im}(c N L C)^{2}}\right)$, not real, value of complex capacitance. This indicates that total prestin charge movement, both in and out of phase with voltage, has been appropriately assessed in past studies. We demonstrate this with a standard electrical model with dielectric loss, with a 2-state kinetic model, and with macro-patch data from the OHC lateral membrane. 


\section{Methods and Results}

The most thorough method to measure membrane capacitance whether or not dielectric loss is present is that outlined by Fernandez et al. (Fernandez et al., 1982). In the absence of dielectric loss, only a real "capacitive" component of complex capacitance is present, whereas in its presence, both real and imaginary "resistive" components are present. Complex capacitance $\left(\mathrm{cC}_{\mathrm{m}}\right)$ is derived from the membrane admittance, $Y_{m}(\omega)$, following removal of the influence of $\mathrm{R}_{s}$ and $\mathrm{R}_{\mathrm{m}}$ from the input admittance, $Y_{i n}(\omega)$ of the simple model in Fig 1 . Thus, complex capacitance is defined as

$$
c C_{m}(\omega)=\frac{Y_{m}(\omega)}{s}=\frac{B_{m}(\omega)}{\omega}-i \frac{G_{m}(\omega)}{\omega}
$$

where $s=i \omega, \omega=2 \pi f$ and $i=\sqrt{-1}$.

The complex components are a consequence of capacitive charge moving both in and out of phase with $\mathrm{AC}$ voltage, and $\mathrm{Im}\left(\mathrm{cC}_{\mathrm{m}}\right)$ does not represent an actual membrane conductance.

A common method to measure membrane capacitance is the phase detection/tracking method (Neher and Marty, 1982; Fidler and Fernandez, 1989) which tracks changes in membrane current that correspond to changes in membrane capacitance. It is not clear how these measures relate to those obtained by complex capacitance estimation. Below we investigate the relationship.

\section{Phase detection/tracking method without dielectric loss}

Interpretation of phase tracking membrane capacitance $\left(C_{m}\right)$ estimates is model dependent (Fig. 1). In the classical phase tracking method, we require to determine the proper phase angle to measure current that corresponds to changes in $\mathrm{C}_{\mathrm{m}}$ (Neher and Marty, 1982; Fidler and Fernandez, 1989), i.e., the angle $\left(\beta_{\omega}\right)$ of the

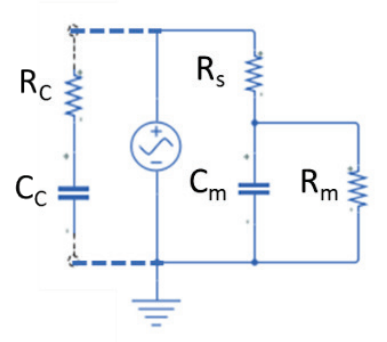

Fig. 1 Phase detection implementation under voltage clamp. Capacitance compensation ( $R_{c}$ and $C_{C}$ ) circuitry is added to the standard electrical model and the proper admittance phase angle and is determined to estimate membrane capacitance, $C_{m}$. $R_{s}$, electrode series resistance; $R_{m}$, membrane resistance. partial derivative $\delta \mathrm{Y} / \delta \mathrm{C}_{\mathrm{m}}$. The change in current is then factored by a gain $\left(H_{c}\right)$ of $1 / \mathrm{abs}\left(\delta \mathrm{Y} / \delta \mathrm{C}_{\mathrm{m}}\right)$ to determine the actual capacitance change (see (Gillis, 1995)). $\beta_{\omega}$ can be determined exactly from the admittance at any two frequencies for the simple model of Fig. 1 (Santos-Sacchi, 2004). However, for the single sine lock-in approach, the angle is estimated empirically. For example, following full capacitance compensation, where the admittance of the compensation circuitry $\left(R_{c}\right.$ and $\left.C_{c}\right)$ exactly matches and is subtracted from the model admittance, a calibrated change in $\mathrm{C}_{\mathrm{c}}$ can be used to estimate $\delta \mathrm{Y} / \delta \mathrm{C}_{\mathrm{m}}$ and its angle. Alternatively, the angle of $\delta \mathrm{Y} / \delta \mathrm{Rs}+\mathrm{pi} / 2$ approximates that $\delta \mathrm{Y} / \delta \mathrm{C}_{\mathrm{m}}$ and can be empirically determined by dithering in a small change $\left(\Delta R_{s}\right)$ in series resistance (Fig. 1). This angle can also be calculated from the input admittance of the model circuit, assuming the recording system is properly calibrated to account for extraneous phase and magnitude deviations (Zierler, 1992). At $\beta_{\omega}$, the real component of dither current is unresponsive to small changes in $C_{m}$ and the imaginary output is then proportional to changes in $\mathrm{C}_{\mathrm{m}}$, which is scaled by $\mathrm{H}_{\mathrm{c}}$.

Analogously, we can work on the admittance of the model circuit. The input admittance at any frequency in the absence of capacitance compensation is

$$
Y_{i n}(\omega)=\frac{C_{m} R_{m} s+1}{R_{m}+R_{s}+C_{m} R_{m} R_{s} s}
$$


where $s=i \omega, \omega=2 \pi f$ and $i=\sqrt{-1}$.

Nulling $Y_{\text {in }}$ with the two-component compensation circuitry requires that both $R_{c}$ and $C_{c}$ be adjusted to attain an input admittance $\left(Y_{C}\right)$ equal to that of the three-component model, $Y_{\text {in. }}$.

$$
Y_{c}(\omega)=Y_{\text {in }}(\omega)=\operatorname{Re}\left(Y_{c}(\omega)\right)+i \operatorname{Im}\left(Y_{c}(\omega)\right)=\operatorname{Re}\left(Y_{\text {in }}(\omega)\right)+i \operatorname{Im}\left(Y_{\text {in }}(\omega)\right)
$$

An equivalent increment in membrane capacitance, $\Delta C_{m}$, is obtained by slightly unbalancing $C_{c}$.

$$
\Delta C_{m}(\omega)=\Delta \operatorname{Im}\left(Y_{c}(\omega)\right) / \omega
$$

The resultant difference admittance, $Y_{\Delta c m}-Y_{i n}$, provides an estimate of $\delta Y / \delta C_{m}$, its angle, $\beta_{\omega}$ and the gain factor, $H_{c}$. Instead, $H_{c}$ can be estimated from $Y_{\text {in }}$ - see eq. 43 in (Gillis, 1995), and more exactly, $\beta_{\omega}$ can be determined from real $\left(A_{0}, A_{1}\right)$ and imaginary $\left(B_{0}, B_{1}\right)$ components of $Y_{\text {in }}$ at any two frequencies $\left(f_{0}, f_{1}\right)$ (Santos-Sacchi, 2004).

$$
\beta_{\omega}=\operatorname{atan}\left[\frac{1}{2} \frac{A_{1}{ }^{2}-2 A_{1} A_{0}+A_{0}{ }^{2}-B_{0}{ }^{2}+B_{1}{ }^{2}}{B_{0}\left(A_{1}-A_{0}\right)}\right]
$$

Using any of these approaches to determine proper inspection angle and gain provides essentially the same outcome that follows.

$Y_{\text {in }}(\omega)$ is then monitored at its angle shifted by $\beta_{\omega}$ to give $Y_{i n}^{*}(\omega)$, whose imaginary component factored by $\mathrm{H}_{c}$ provides any subsequent changes in $\mathrm{C}_{\mathrm{m}}$.

$$
\begin{gathered}
\varnothing(\omega)=\angle\left(Y_{\text {in }}(\omega)\right)=\operatorname{atan}\left(\frac{\operatorname{Im}\left(Y_{\text {in }}(\omega)\right)}{\operatorname{Re}\left(Y_{\text {in }}(\omega)\right)}\right) \\
Y_{\text {in }}^{*}(\omega)=Y_{\text {in }}(\omega) \cdot e^{\left(-i\left(\varnothing(\omega)-\beta_{\omega}(\omega)\right)\right)}
\end{gathered}
$$

with the imaginary component corresponding to changes in $\mathrm{C}_{\mathrm{m}}$.

$$
C_{m}(\omega)=\operatorname{Im}\left(Y_{i n}^{*}(\omega)\right) \cdot H_{C}
$$

$C_{m}$ estimated in this way is independent of stimulus frequency, as expected.

\section{Phase tracking with Dielectric loss}

Dielectric loss is most simply modelled by inserting a resister $\left(\mathrm{R}_{\mathrm{DiL}}\right)$ in series with a capacitance $\left(C_{\text {Dil }}\right)$ (Fernandez et al., 1982). $R_{\text {DiL, }}$ the equivalent series resistance (ESR), is hidden from physical inspection and cannot be removed, as it is intrinsic to $C_{D i L}$. Fig. 2 illustrates the circuit used to model the addition of such loss to linear membrane

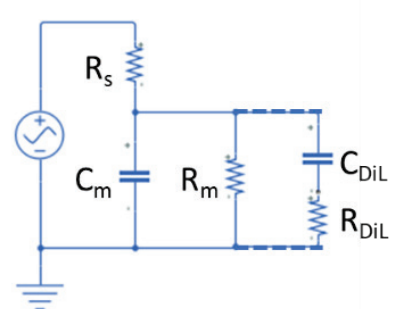

Fig. 2 Dielectric loss is modeled by adding a lossy capacitor $\left(C_{D i L}\right.$ in series with $\mathrm{R}_{\mathrm{DiL}}$ ) parallel to the membrane capacitance, $C_{m}$. capacitance, $\mathrm{C}_{\mathrm{m}}$. The resistance results in a dissipation of power into the resistor, generating heat, and can be monitored with the imaginary component of complex capacitance, $\operatorname{Im}\left(\mathrm{cC}_{\mathrm{m}}\right)$. What does standard phase tracking measure in the presence of dielectric loss? To mimic the addition of voltage-dependent OHC NLC, $\beta_{\omega}$ and $\mathrm{H}_{\mathrm{C}}$ were first determined in the absence of dielectric loss. This would be equivalent to recording from $\mathrm{OHCs}$ at very positive 
bioRxiv preprint doi: https://doi.org/10.1101/2022.01.01.474702; this version posted January 11, 2022. The copyright holder for this preprint (which was not certified by peer review) is the author/funder. All rights reserved. No reuse allowed without permission.

Santos-Sacchi

$1 / 12 / 202212: 10 \mathrm{AM}$

membrane potentials (e.g., $+160 \mathrm{mV}$ ) where NLC is lacking. Membrane capacitance is then tracked before and after the addition of a lossy capacitor in parallel with $\mathrm{C}_{\mathrm{m}}$. When followed, the lock-in approach detailed above shows that the imaginary component of input admittance tracked at $\beta_{\omega}$, corresponds to $\mathrm{Abs}\left(\mathrm{cC}_{\mathrm{m}}\right)$, thus providing an estimate of $C_{m}$ across frequency that includes capacitor charge movement both in and out of phase with AC voltage. A Matlab script in the s-domain (Fig. 3A, B) confirms that phase tracking at most frequencies closely follows $A b s\left(c C_{m}\right)$. Note that at low frequencies $\operatorname{Re}\left(c C_{m}\right)$ tracks $A b s\left(c C_{m}\right)$, but at high frequencies $\operatorname{Im}\left(\mathrm{cC}_{\mathrm{m}}\right)$ tracks $\mathrm{Abs}\left(\mathrm{cC} \mathrm{C}_{\mathrm{m}}\right)$. The cut-off frequency of $A b s\left(\mathrm{cC}_{\mathrm{m}}\right)$ depends inversely on the magnitude of $R_{\text {Dil }}$ or dielectric loss.

\section{Phase tracking with a 2-state voltage-dependent kinetic model}

Fernandez et al. (Fernandez et al., 1982) pointed out that Eyring rate models exhibit dielectric loss characteristics. Consequently, real and imaginary components of voltage-dependent capacitance are generated in a simple 2-state kinetic model of prestin (Santos-Sacchi et al., 2021), where expanded (X) and compact (C) state populations redistribute during changes in membrane voltage.

$$
\begin{gathered}
\mathrm{X} \underset{\beta}{\stackrel{\alpha}{\rightleftharpoons}} \mathrm{C} \\
\alpha=\alpha_{0} \exp \left(\frac{z F\left(V_{m}-V_{h}\right)}{2 R T}\right) \\
\beta=\beta_{0} \exp \left(\frac{z F\left(V_{m}-V_{h}\right)}{2 R T}\right)
\end{gathered}
$$

Both forward and backward rates ( $\alpha, \beta$, respectively) are governed solely by membrane voltage $\left(V_{m}\right)$ about a characteristic potential, $V_{h}$, where charge is distributed equally on either side of the membrane field. $z$ denotes the unitary particle charge $\left(\mathrm{e}^{-} \mathrm{X}\right.$ distance travelled perpendicular to the membrane field). F, R and T have their usual meanings. $V_{h}$ is set to zero $m V$.
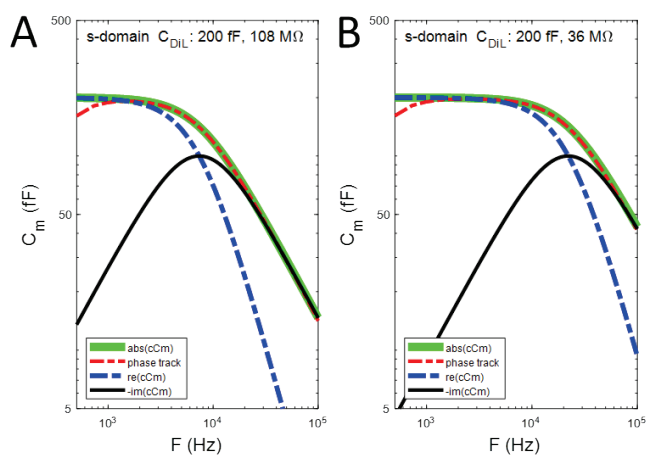

6
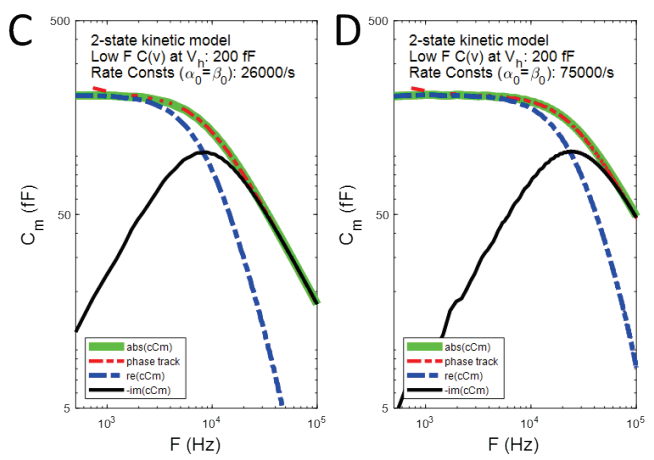

Fig. $3 C_{m}$ estimates returned by complex and phase-tracking methods as a function of dielectric loss analyzed in the s-domain in Matlab (A, B) or as a function of 2-state kinetic transition rates analyzed in the time domain in Matlab Simulink (C, D) across frequency. Phase tracking provides estimates of $\mathrm{Abs}\left(\mathrm{cC}_{\mathrm{m}}\right)$ across frequency and depends on the degree of dielectric loss or transition rates, thus including influences of charge movement in and out of phase with voltage. For the kinetic model, forward and backward rate constants are the same and linear capacitance is subtracted prior to plotting. 
bioRxiv preprint doi: https://doi.org/10.1101/2022.01.01.474702; this version posted January 11, 2022. The copyright holder for this preprint (which was not certified by peer review) is the author/funder. All rights reserved. No reuse allowed without permission.

Santos-Sacchi

$1 / 12 / 202212: 10 \mathrm{AM}$

As above, measures are made relative to a holding voltage where voltage-dependent capacitance is absent, i.e., $+200 \mathrm{mV}$. Here, again (Fig. 3C, D), phase tracking estimates at the voltage $\left(V_{h}\right)$ of peak $C_{m}(v)$ correspond to measures of $\mathrm{Abs}\left(\mathrm{cC}_{\mathrm{m}}(\mathrm{v})\right)$ across frequency, with cut-off frequencies of $\mathrm{Abs}\left(\mathrm{cC}_{\mathrm{m}}(\mathrm{v})\right)$ increasing with the particular transition rate constants $(26000 / \mathrm{s}$ or $75000 / \mathrm{s})$, with $\alpha_{0}=\beta_{0}$. The frequency cut-off at $V_{h}$ is given by $1 /(2 \pi \tau)$, with $\tau=1 /\left(\alpha_{0}+\beta_{0}\right)$.

\section{Voltage-dependent nonlinear capacitance in OHC membrane patches}

Voltage-dependent nonlinear capacitance (NLC) arises from restricted sensor charge movement (displacement currents) within membrane bound, voltage-dependent proteins (Fernandez et al., 1982; Santos-Sacchi, 1991; Kilic and Lindau, 2001). We find that in OHCs, complex NLC (cNLC) presents significant dielectric loss, i.e., an Im(cNLC) component, in measures of prestin (SLC26a5) generated capacitance (Santos-Sacchi et al., 2021). We model/fit NLC as a molecular capacitor obeying Boltzmann statistics (Santos-Sacchi, 1991).

$$
\begin{gathered}
C_{m}=N L C+C_{s a}+C_{\text {lin }}=Q_{\max } \frac{\text { ze }}{k_{B} T} \frac{b}{(1+b)^{2}}+C_{s a}+C_{\text {lin }} \\
\text { where } b=\exp \left(-z e \frac{V_{m}-V_{h}}{k_{B} T}\right), C_{s a}=\frac{\Delta C_{s a}}{\left(1+b^{-1}\right)}
\end{gathered}
$$

$\mathrm{Q}_{\max }$ is the maximum nonlinear charge moved, $\mathrm{V}_{\mathrm{h}}$ is voltage at peak capacitance or equivalently, at half-maximum charge transfer, $V_{m}$ is membrane potential, $z$ is valence, $C_{\text {lin }}$ is linear membrane capacitance, e is electron charge, $k_{B}$ is Boltzmann's constant, and $T$ is absolute temperature. $C_{s a}$ is a component of capacitance that characterizes sigmoidal changes in specific membrane capacitance, with $\Delta \mathrm{C}_{\mathrm{sa}}$ referring to the maximal change at very negative voltages (Santos-Sacchi and Navarrete, 2002; Santos-Sacchi and Song, 2014).

A

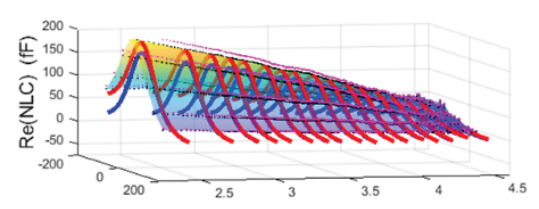

B

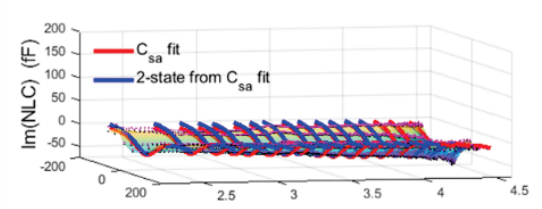

C

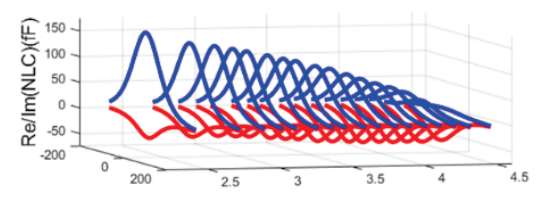

D

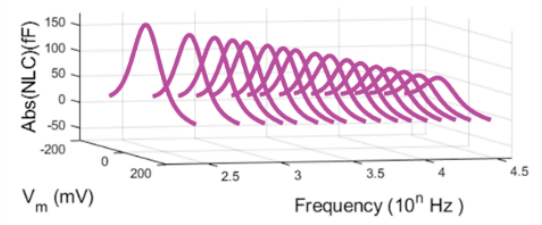

E

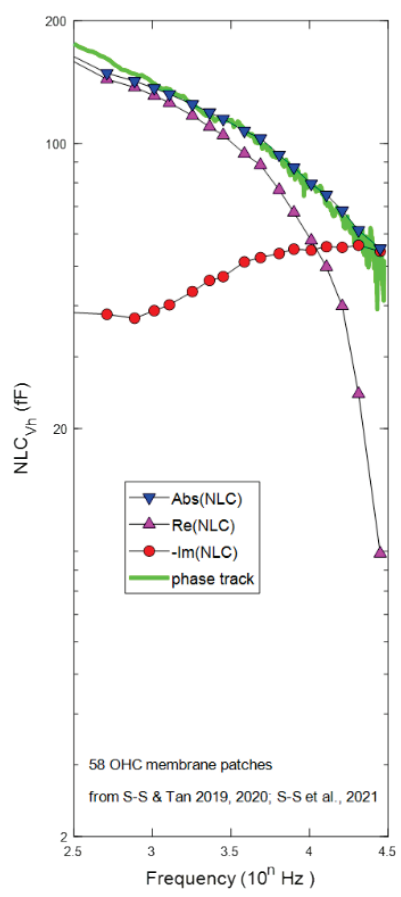

Fig. 4 Real and imaginary components of macro-patch NLC with comparisons of $\mathrm{Abs}(\mathrm{cNLC})$ and phase tracking estimates. A) Real component of complex NLC across frequency. Blue dots are mean, red dots are +SE. Fits are made to eq.11 to extract the 2state (blue line) response at selected frequencies. B) Imaginary component of complex NLC. Magnitude increases with frequency, with less than a full reciprocal trade-off with real NLC. C) Plot of the 2-state fits. D) Plot of the absolute magnitude of NLC, i.e., $\sqrt{\operatorname{Re}(c N L C)^{2}+\operatorname{Im}(c N L C)^{2}}$, showing a continuous reduction of prestin activity across frequency. E) Plots of NLC near $\mathrm{V}_{\mathrm{h}}(-40$ $\mathrm{mV})$. Real NLC is much lower pass than $\mathrm{Abs}(\mathrm{cNLC})$. Notably, phase tracking estimates of NLC (green line) correspond to those of $\mathrm{Abs}(\mathrm{cNLC})$. Phase tracking results were obtained from admittance analysis of averaged raw currents. Complex NLC was determined as previously described (SantosSacchi et al., 2021). 
Fig. 4A-D shows components of complex NLC measured in lateral membrane macro-patches of the $\mathrm{OHC}$ as a function of holding voltage and frequency. Data sets are combined and reanalyzed from our recent publications (Santos-Sacchi and Tan, 2019, 2020; Santos-Sacchi et al., 2021). In Fig. 4E, fitted NLC components measured near $V_{h}$ (from Fig. 4C, D) are plotted across frequency, as well as NLC $\mathrm{Vh}_{\mathrm{h}}$ estimates determined from the phase tracking approach detailed above (eq. 3-8), relative to measures at $+160 \mathrm{mV}$ holding potential. Phase tracking estimates were smoothed by running average across 35 indices at $24 \mathrm{~Hz}$ resolution for frequencies above $10 \mathrm{kHz}$. As with model evaluations, it can be seen that phase tracking estimates of NLC (green line) correspond to Abs(cNLC) (blue downward triangles).

\section{Discussion}

Phase tracking techniques that have been used to measure OHC NLC in patches evaluate to close estimates of $\mathrm{Abs}(\mathrm{CNLC})$, representing total charge moved by prestin's voltage sensors, both in and out of phase with voltage. Indeed, the frequency response of Re(cNLC) and Abs(cNLC) differ, with Abs(cNLC) being wider in bandwidth. Note that at low frequencies $\operatorname{Re}(\mathrm{cNLC})$ tracks $A b s(\mathrm{cNLC})$, but at high frequencies $\mathrm{Im}(\mathrm{cNLC})$ is predicted by modelling to track $\mathrm{Abs}(\mathrm{CNLC})$, indicating that $\mathrm{Abs}(\mathrm{cNLC})$ measures fully characterize the low-pass behavior of $\mathrm{Im}(\mathrm{cNLC})$ at very high frequencies. Thus, past frequency response measures of OHC NLC have not missed contributions from dielectric loss. In fact, the phase tracking data of Gale and Ashmore (Gale and Ashmore, 1997) and the Abs(cNLC) data of Santos-Sacchi and Tan (SantosSacchi and Tan, 2020) are in good agreement, each consistent with reductions in OHC NLC as a power function of frequency. It should also be noted that measures of Abs(cNLC), which phase tracking provides, cannot be used to predict the underlying real and imaginary components since we have found that the frequency response of real and imaginary NLC components are individually susceptible to membrane tension, despite stability of Abs(cNLC) across frequency (Santos-Sacchi et al., 2021).

Why does phase tracking return Abs(cNLC)? The technique strives to minimize the real component of admittance (or current) by rotating its measurement angle, thus shifting any real component into the imaginary component detector. Rotating the angle of any complex number in order to zero the real component will give $\operatorname{Im}(A+B i)=A b s(A+B i)$. The detection of the $A b s(c N L C)$ value is thus an unintended quirk of the method.

To summarize, we have shown in simple models and in biophysical data that NLC assessment with phase tracking methods provide close estimates of $\mathrm{Abs}(\mathrm{cNLC})$, i.e., $\sqrt{\operatorname{Re}(c N L C)^{2}+\operatorname{Im}(c N L C)^{2}}$, not $\operatorname{Re}(\mathrm{cNLC})$, as previously claimed (Rabbitt, 2020). Consequently, prestin performance has been realistically appraised during the last few decades, and its low-pass characteristic remains a limiting factor for the protein's influence on cochlear amplification at very high acoustic frequencies. Finally, should dielectric loss be present in any cell's membrane capacitance, for example as expected from channel gating charge movements, estimates of vesicle release by $C_{m}$ phase tracking may be impacted in a manner not previously appreciated; that is, $C_{m}$ estimates will be influenced not only by capacitive gating charge components (Horrigan and Bookman, 1994) but also by resistive gating charge components. 
bioRxiv preprint doi: https://doi.org/10.1101/2022.01.01.474702; this version posted January 11, 2022. The copyright holder for this preprint (which was not certified by peer review) is the author/funder. All rights reserved. No reuse allowed without permission.

Santos-Sacchi

1/12/2022 12:10 AM

\section{References}

Ashmore JF (1990) Forward and reverse transduction in the mammalian cochlea. Neurosci Res Suppl 12:S39-S50.

Bavi N, Clark MD, Contreras GF, Shen R, Reddy B, Milewski W, Perozo E (2021) Cryo-EM Structures of Prestin and the Molecular Basis of Outer Hair Cell Electromotility. bioRxiv doi: 101101/20210806455374.

Butan C, Song Q, Bai J-P, Tan WJT, Navaratnam D, Santos-Sacchi J (2021) Single particle cryo-EM structure of the outer hair cell motor protein prestin. bioRxiv doi: 101101/20210803454998.

Fang J, Izumi C, Iwasa KH (2010) Sensitivity of prestin-based membrane motor to membrane thickness. Biophys J 98:2831-2838.

Fernandez JM, Bezanilla F, Taylor RE (1982) Distribution and kinetics of membrane dielectric polarization. II. Frequency domain studies of gating currents. JGenPhysiol 79:41-67.

Fidler N, Fernandez JM (1989) Phase tracking: an improved phase detection technique for cell membrane capacitance measurements. Biophys J 56:1153-1162.

Gale JE, Ashmore JF (1997) An intrinsic frequency limit to the cochlear amplifier. Nature 389:63-66.

Ge J, Elferich J, Dehghani-Ghahnaviyeh S, Zhao Z, Meadows M, Gersdorff Hv, Tajkhorshid E, Gouaux E (2021) Molecular mechanism of prestin electromotive signal amplification. Cell doi: 10.1016/j.cell.2021.07.034.

Gillis KD (1995) Techniques for Membrane Capacitance Measurements. In: Single Channel Recording (Sakmann B, Neher E, eds), pp 155-198. New York: Plenum Press.

Horrigan FT, Bookman RJ (1994) Releasable pools and the kinetics of exocytosis in adrenal chromaffin cells. Neuron 13:1119-1129.

Kilic G, Lindau M (2001) Voltage-dependent membrane capacitance in rat pituitary nerve terminals due to gating currents. Biophys J 80:1220-1229.

Neher E, Marty A (1982) Discrete changes of cell membrane capacitance observed under conditions of enhanced secretion in bovine adrenal chromaffin cells. Proc Natl Acad Sci U S A 79:6712-6716.

Rabbitt RD (2020) The cochlear outer hair cell speed paradox. Proc Natl Acad Sci U S A 117:21880-21888.

Santos-Sacchi J (1990) Fast outer hair cell motility: how fast is fast? In: The Mechanics and Biophysics of Hearing (Dallos P, Geisler CD, Matthews JW, Ruggero MA, Steele CR, eds), pp 69-75. Berlin: Springer-Verlag.

Santos-Sacchi J (1991) Reversible inhibition of voltage-dependent outer hair cell motility and capacitance. J Neurosci 11:3096-3110.

Santos-Sacchi J (2004) Determination of cell capacitance using the exact empirical solution of $\mathrm{dY} / \mathrm{dCm}$ and its phase angle. Biophys J 87:714-727.

Santos-Sacchi J (2019) The speed limit of outer hair cell electromechanical activity. HNO 67:159-164.

Santos-Sacchi J, Navarrete E (2002) Voltage-dependent changes in specific membrane capacitance caused by prestin, the outer hair cell lateral membrane motor. Pflugers Arch 444:99-106.

Santos-Sacchi J, Wu M (2004) Protein- and lipid-reactive agents alter outer hair cell lateral membrane motor charge movement. JMembrBiol 200:83-92.

Santos-Sacchi J, Song L (2014) Chloride and Salicylate Influence Prestin-Dependent Specific Membrane Capacitance: Support for the Area Motor Model. J Biol Chem.

Santos-Sacchi J, Tan W (2018) The Frequency Response of Outer Hair Cell Voltage-Dependent Motility Is Limited by Kinetics of Prestin. J Neurosci 38:5495-5506.

Santos-Sacchi J, Tan W (2019) Voltage Does Not Drive Prestin (SLC26a5) Electro-Mechanical Activity at High Frequencies Where Cochlear Amplification Is Best. iScience 22:392-399.

Santos-Sacchi J, Tan W (2020) Complex nonlinear capacitance in outer hair cell macro-patches: effects of membrane tension. Sci Rep 10:6222. 
bioRxiv preprint doi: https://doi.org/10.1101/2022.01.01.474702; this version posted January 11, 2022. The copyright holder for this preprint (which was not certified by peer review) is the author/funder. All rights reserved. No reuse allowed without permission.

Santos-Sacchi

Santos-Sacchi J, Iwasa KH, Tan W (2019) Outer hair cell electromotility is low-pass filtered relative to the molecular conformational changes that produce nonlinear capacitance. J Gen Physiol 151:13691385.

Santos-Sacchi J, Navaratnam D, Tan WJT (2021) State dependent effects on the frequency response of prestin's real and imaginary components of nonlinear capacitance. Sci Rep 11:16149.

Sfondouris J, Rajagopalan L, Pereira FA, Brownell WE (2008) Membrane composition modulates prestinassociated charge movement. JBiolChem 283:22473-22481.

Zhai F, Song L, Bai JP, Dai C, Navaratnam D, Santos-Sacchi J (2020) Maturation of Voltage-induced Shifts in SLC26a5 (Prestin) Operating Point during Trafficking and Membrane Insertion. Neuroscience 431:128-133.

Zierler K (1992) Simplified method for setting the phase angle used in capacitance measurements in studies of exocytosis. Biophys J 63:854-856. 